Volume 8

Number 2 Student Articles Edition

Article 1

2-16-2022

\title{
Content Moderation Issues Online: Section 230 Is Not to Blame
}

Reese D. Bastian

Texas A\&M University School of Law (Student), reeseb2@tamu.edu

Follow this and additional works at: https://scholarship.law.tamu.edu/journal-of-property-law

Part of the Communications Law Commons, Intellectual Property Law Commons, Internet Law Commons, and the Property Law and Real Estate Commons

\section{Recommended Citation}

Reese D. Bastian, Content Moderation Issues Online: Section 230 Is Not to Blame, 8 Tex. A\&M J. Prop. L. 43 (2022).

Available at: https://doi.org/10.37419/JPL.V8.I2.1

This Notes \& Comments is brought to you for free and open access by Texas A\&M Law Scholarship. It has been accepted for inclusion in Texas A\&M Journal of Property Law by an authorized editor of Texas A\&M Law Scholarship. For more information, please contact aretteen@law.tamu.edu. 


\title{
CONTENT MODERATION ISSUES ONLINE: SECTION 230 IS NOT TO BLAME
}

\author{
Reese D. Bastian ${ }^{\dagger}$
}

\begin{abstract}
Section 230 of the Communications Decency Act ("Section 230") is the glue that holds the Internet - as we know it today-together. Section 230 says, "No provider or user of an interactive computer service shall be treated as the publisher or speaker of any information provided by another information content provider." Simply put, Section 230 says that websites or platforms are not liable for content posted by third parties. ${ }^{2}$ There are many critics who attribute the maladies of the online world to Section 230. Section 230 presents issues such as over-moderation by Interactive Computer Service ("ICS") providers that can go as far as to be considered censorship and under-moderation that leads to uncomely and even unsafe cyberspaces. Repealing or weakening Section 230 will not fix over-moderation-or even under-moderation - online but allowing and fostering competition in the tech sector will.
\end{abstract}

DOI: https://doi.org/10.37419/JPL.V8.I2.1

$\dagger$ Reese D. Bastian is a J.D. Candidate at Texas A\&M University School of Law with a graduation date of May 2022. Before enrolling in law school, Reese received a Bachelor of Science in Electrical Engineering from Brigham Young University. His passion for technology and law are the focus of his career aspirations. He would like to thank Professor Hannah Bloch-Wehba for her passion and knowledge of Internet Law that inspired the topic of this Article. Furthermore, he wishes to express many thanks for her thoughtful feedback, encouragement, and guidance throughout the writing process. Many thanks also to his father, Stan, and his brother, Bryce, for their help in the editing process. Finally, thank you to those who inspire him most, his loving wife, Brittney, and his sweet little daughter, Brighton. This Article reflects developments through March 2021, when it was finalized for publication.

1. 47 U.S.C. $\$ 230(\mathrm{c})(1)$.

2. Jess Miers, Section 230: What You Don't Know Might Destroy the Internet, YouTuBE: TEDX TALKS (Apr. 11, 2019), https://www.youtube.com/watch ?v=7EGRRM_kMac\&feature=youtu.be\&t=585 [https://perma.cc/QH7V-XNBJ]. 


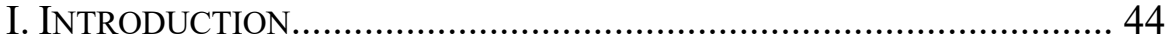

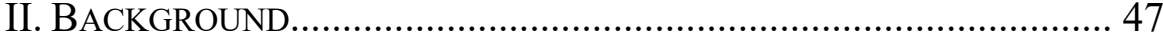

A. Section 230: Shaping the Internet ………………….......... 49

B. Problems Associated with Section 230.............................. 52

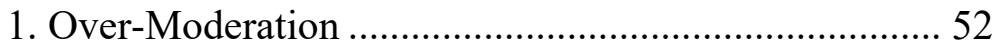

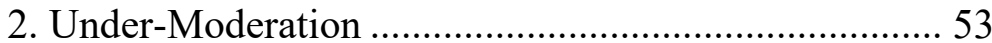

III. THE Two TYPeS OF PROPOSITIONS TO "FIX" SECTION 230 ……... 54

A. Stripping Section 230 Protections...................................... 55

1. Executive Order on Preventing Online Censorship..... 55

2. The Stop the Censorship Act ......................................... 57

3. Reform May Increase Private Governance ................... 59

B. Making Section 230 Operate Like Common Carriage ...... 62

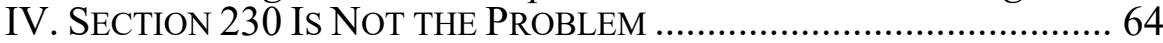

A. What is Good About Section 230?..................................... 64

B. How to "Fix" Section 230 Without Changing or

Weakening It........................................................................ 66

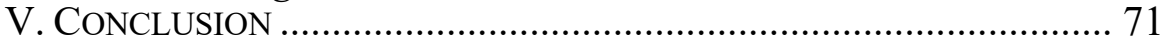

\section{INTRODUCTION}

Mass media of the twentieth century - print newspapers, magazines, radio broadcasts, and television broadcasts - was very different from the mass media of today. ${ }^{3}$ Mass media of the twentieth century included forms of speech that were subject to a dualistic model of regulation, meaning that two actors were involved - the media company and the government. ${ }^{4}$ The government regulated the speech of each publishing house, movie house, newspaper, radio station, or television station and governed them directly and individually, employing the threat of fines, penalties, or imprisonment. ${ }^{5}$ Because these mass media companies were editors and publishers of the content they provided, they faced the broad liability that comes with being editors and publishers. ${ }^{6}$ Then, and even now, when a third party publishes speech or

3. Jack M. Balkin, Free Speech Is a Triangle, 118 CoLuM. L. REv. 2011, 2013 (2018).

4. Id. at 2013 .

5. Id. at $2013,2015$.

6. Jack M. Balkin, Free Speech in the Algorithmic Society: Big Data, Private Governance, and New School Speech Regulation, 51 U.C. DAVIS L. REV. 1149, 1192 (2018). 
creates content, mass media companies are potentially subject to a form of secondary liability known as intermediary liability. ${ }^{7}$

The new "mass media outlets" came to be because of the Internet, often taking the form of interactive social media platforms, where a vast number of users (third parties) post their own content for others to see. This arrangement is a triangle with three actors instead of two. ${ }^{8}$ Those three actors are governments, ICS providers, and third-party users. ${ }^{9}$ Big Tech ICS providers, such as Facebook, Google, YouTube, and Twitter, have built Interactive Computer Services ("ICSs") on a cycle of content generation that relies on their millions of users to produce and provide content to all of their other users. ${ }^{10}$ Under the regulatory framework applied to traditional mass media of the twentieth century, these ICS providers would be subject to intermediary liability for all third-party content. ${ }^{11}$ In the United States, however, Section 230 limits intermediary liability for ICS providers. ${ }^{12}$ Before Section 230 was enacted, laws governing intermediary liability for ICS providers were "hyper-vigilant" of those editing or moderating online speech of third parties - meaning that any filtering or moderating of third-party content by ICS providers would likely trigger liability - but upon passage of Section 230, the laws have transitioned into a "hyper-protective" phase where ICS providers are shielded from liability even when they filter or moderate third-party content. ${ }^{13}$

For the past couple of decades, the sentiment has been that generally the Internet provides opportunities for free speech and promotes the marketplace of ideas. However, in recent years that sentiment has changed. ${ }^{14}$ There are many critics who attribute maladies of the online world to Section 230. For example, on May 28, 2020, President Trump issued an executive order titled: Executive Order on Preventing Online Censorship ("Trump Executive Order"). ${ }^{15}$ That executive order states

7. See Stratton Oakmont, Inc. v. Prodigy Servs. Co., No. 031063/94, 1995 WL 323710 (N.Y. Sup. Ct. May 24, 1995).

8. Balkin, supra note 3, at 2055.

9. Id.

10. Balkin, supra note 6, at 1192; Balkin, supra note 3, at 2022.

11. See Prodigy, 1995 WL 323710 at $* 5$.

12. 47 U.S.C. $\$ 230$.

13. Danielle Keats Citron, Cyber Civil Rights, 89 B.U. L. ReV. 61, 116 (2009).

14. Mike Masnick, Protocols, Not Platforms 4 (2019), https://knightcolumbia.org/content/protocols-not-platforms-a-technological-approach-to-freespeech [https://perma.cc/9F9Z-D6ES].

15. Exec. Order No. 13925, 85 Fed. Reg. 34,079 (May 28, 2020). 
that "we cannot allow a limited number of online platforms to hand pick the speech that Americans may access and convey on the internet." 16 The Trump Executive Order further alleges that social media companies, like Twitter, Facebook, Instagram, and YouTube, possess the power to shape online content through censoring, deleting, and controlling what information can and cannot be seen online. ${ }^{17}$ President Trump points to Section 230 as the source of this problem, however, tinkering with Section 230 may not be the best way to fix these issues.

Repealing or drastically changing Section 230 is not the way to fix content moderation and free speech issues online. There are essentially two categories of propositions to "fix" Section 230. The first group of propositions essentially aims to strip Section 230 protections. This is done, for example, by imposing duties of neutrality or obligations to take down certain third-party content in order for ICS providers to "earn" Section 230 protections. The second group of propositions focuses on common carriage solutions and tries to "fix" Section 230 with federal or other regulations that would make social media a public utility. ${ }^{18}$ This Article argues that neither of these approaches presents a viable way to resolve the many content moderation and free speech issues that exist online. The better approach is to leave Section 230 as it is and combat anticompetitive issues by using antitrust law and allowing and fostering competition against Big Tech in the ICS sector.

Section II begins by describing Section 230, the development of common law surrounding this legislation, and the different types of problematic content moderation that arise under Section 230. Section III examines, analyzes, and criticizes the categories of approaches to "fix" Section 230 and specific propositions to substantially change or repeal Section 230, such as the Trump Executive Order and the recently proposed Stop the Censorship Act, as well as proposals to reclassify certain Big tech ICSs as common carriers subject to non-discrimination regulation. Finally, Section IV describes the benefits of

16. $I d$.

17. Id.

18. See Bobby Allyn, Justice Clarence Thomas Takes Aim at Tech and Its Power 'To Cut Off Speech,' NAT'L. PUB. RADIO (Apr. 5, 2021), https://www.npr.org/2021 /04/05/984440891/justice-clarence-thomas-takes-aims-at-tech-and-its-power-to-cut -off-speech [https://perma.cc/59HX-HZDD]. 
Section 230, and argues that repealing or weakening Section 230 will not fix over-moderation - or even under-moderation - online, but rather allowing and fostering competition against Big Tech in the ICS sector through antirust and fundamental changes to the digital infrastructure of ICSs will fix the problem.

\section{BACKGROUND}

Ever since the creation of the World Wide Web, law and regulation have played major roles in shaping the Internet of today. In the United States, companies like Twitter, Facebook, Instagram, and YouTube possess the power to shape online content through censoring, deleting, and controlling what content can and cannot be seen online. ${ }^{19}$ The services provided by Big Tech ICSs like Facebook and Google are social media platforms used widely-seemingly, by everyone. ${ }^{20}$ Because of the network effect, bigger is better for these mega platforms and this creates a sort of natural monopoly. ${ }^{21}$ The network effect is the "well-known phenomenon that systems may quickly increase in value as the number of users grow, and similarly, that the network may have little, or no, value without large scale adoption."22 More users, on top of the millions already using these platforms, only increases the value of the social networks, not only for the users, but also the ICS providers. ${ }^{23}$ This is because they depend on collected data from their huge mass of users to sell targeted ads to third parties. ${ }^{24}$

19. Exec. Order No. 13925, 85 Fed. Reg. at 34,079; see also Adam Candeub, Bargaining for Free Speech: Common Carriage, Network Neutrality, and Section 230, 22 YALE J.L. \& TECH. 391, 423 (2020).

20. See Sarah Joseph, Why the Business Model of Social Media Giants Like Facebook is Incompatible with Human Rights, THE CONVERSATION (Apr. 2, 2018, 3:59 PM), https://theconversation.com/why-the-business-model-of-social-media-giantslike-facebook-is-incompatible-with-human-rights-94016 [https://perma.cc/WB2B97F6].

21. John M. Yun, Does Antitrust Have Digital Blind Spots?, 72 S.C. L. REV. 305, 314-17 (2020); see also Sarah Joseph, Why the Business Model of Social Media Giants Like Facebook is Incompatible with Human Rights, THE CONVERSATION (Apr. 2, 2018, 3:59 PM), https://theconversation.com/why-the-business-model-ofsocial-media-giants-like-facebook-is-incompatible-with-human-rights-94016 [https://perma.cc/WB2B-97F6].

22. See Spencer Weber Waller, Antitrust and Social Networking, 90 N.C. L. REV . 1771, 1787 (2012).

23. See id. at 1788 .

24. Sarah Joseph, Why the Business Model of Social Media Giants Like Facebook is Incompatible with Human Rights, THE CONVERSATION (Apr. 2, 2018, 3:59 PM), https://theconversation.com/why-the-business-model-of-social-media-giants- 
Because these mega platforms form monopolies, it is hard for users to stop using their services because there are no viable alternatives. ${ }^{25}$ This has led to vast numbers of users on platforms such as Facebook and Twitter - who each agree to the terms of service and are then governed by those terms as they use the platform to create and post their own content. ${ }^{26}$ Luckily for these platforms, Section 230 offers broad immunity from intermediary liability when they moderate content and places no obligations on the platforms in return. ${ }^{27}$ These platforms have been free to moderate content in the way they think best, however, not everyone on these platforms agrees with the way content is being moderated. Some want these platforms to enforce certain social norms through targeted curation - and even censorship - of thirdparty content, while others are willing to part with their free-market ideals in exchange for forced neutrality online in order to facilitate a different version of social norms. ${ }^{28}$

Some argue that these ICSs are open to the public in such a way that should allow people to assert their constitutional rights online. ${ }^{29}$ Because the Supreme Court has declared the Internet to be the modern-day public square, ${ }^{30}$ Internet users should not have to fear suppression of speech online by the government, but that says nothing about suppression of speech online by ICS providers on their privately owned platforms. Indeed, the government is not entirely in control of what happens online. Because of Section 230, companies like Facebook have extensive control over what content they allow on their platform and have the power to discriminate against content they deem inappropriate for their platform. ${ }^{31}$

like-facebook-is-incompatible-with-human-rights-94016 [https://perma.cc/WB2B97F6].

25. See Yun, supra note 21, at 314; see also Bobby Allyn, Justice Clarence Thomas Takes Aim at Tech and Its Power 'To Cut Off Speech,'NAT'L. PuB. RADIO (Apr. 5, 2021), https://www.npr.org/2021/04/05/984440891/justice-clarencethomas-takes-aims-at-tech-and-its-power-to-cut-off-speech [https://perma.cc/59HX -HZDD]; MASNICK, supra note 14.

26. See Waller, supra note 22, at 1791.

27. See Danielle Keats Citron \& Benjamin Wittes, The Internet Will Not Break: Denying Bad Samaritans $\oint 230$ Immunity, 86 ForDHAM L. REV. 401, 403 (2017).

28. See Nina Brown, Regulatory Goldilocks: Finding the Just and Right Fit for Content Moderation on Social Platforms, 8 TEX. A\&M L. REV. 451 (2021).

29. Tyler Lane, The Public Forum Doctrine in the Modern Public Square, 45 OHIO N.U. L. REV. 465, 499 (2019).

30. Packingham v. North Carolina, 137 S. Ct. 1730, 1737 (2017).

31. Objectionable Content, FACEBOOK, https://www.facebook.com 


\section{A. Section 230: Shaping the Internet}

Section 230 is the glue that holds the Internet-as we know it today-together. Its history is telling, and it started in the early days of the Internet. Section 230 says, "No provider or user of an interactive computer service shall be treated as the publisher or speaker of any information provided by another information content provider." 32 Simply put, Section 230 says that websites or platforms are not liable for content posted by third parties. ${ }^{33}$ Section 230 also provides ICS providers with immunity from actions brought against them on account of restricting access to or availability of material posted by a third party. ${ }^{34}$ Section 230 states:

No provider or user of an interactive computer service shall be held liable on account of - any action voluntarily taken in good faith to restrict access to or availability of material that the provider or user considers to be obscene, lewd, lascivious, filthy, excessively violent, harassing, or otherwise objectionable, whether or not such material is constitutionally protected. ${ }^{35}$

Thus, under Section 230, even though platforms may facilitate the publication or distribution of third-party content, they are not considered editors or publishers of that content. ${ }^{36}$ ICS providers may also restrict access to material posted by third parties and are not liable for any actions brought against them on account of such restrictions. ${ }^{37}$

But how and why did the sweeping protection now offered by Section 230 come to be? Before Section 230, laws governing intermediary liability for ICS providers were "hyper-vigilant" of those editing and publishing the online speech of third parties, but upon the passage of Section 230, and following case law development, the laws have transitioned into a "hyper-protective" phase. ${ }^{38}$ During the "hyper-vigilant" stage of intermediary liability, before Section 230, when ICS providers did filter and moderate some of the third-party content on

/communitystandards/objectionable_content [https://perma.cc/KT2H-CTS4].

32. 47 U.S.C. $\$ 230(\mathrm{c})(1)$.

33. Jess Miers, Section 230: What You Don't Know Might Destroy the Internet, YouTuBE: TEDX TALKS (Apr. 11, 2019), https://www.youtube.com/watch $? \mathrm{v}=7 \mathrm{EGRRM} \mathrm{kMac} \&$ feature=youtu.be\&t=585 [https://perma.cc/QH7V-XNBJ].

34. $\S 230(\overline{\mathrm{c}})(2)$.

35. $\$ 230(\mathrm{c})(2)(\mathrm{A})$.

36. $\S 230(\mathrm{c})(1)$.

37. $§ 230(\mathrm{c})(2)$.

38. Citron, supra note 13, at 116. 
their platforms, those ICS providers could be liable for all third-party content posted onto their sites because they were considered editors and publishers of all the third-party content on their platform. ${ }^{39}$

The passage of Section 230 responded to cases like Stratton Oakmont, Inc. v. Prodigy Services Co. ("Prodigy"), where an ICS provider was held liable for defamatory content published to its website by a third party. ${ }^{40}$ The court in Prodigy reasoned that because Prodigy Services Co. exercised editorial discretion by algorithmically screening for offensive language and manually deleting comments that were offensive or of bad taste, they acted as the editors and publishers of thirdparty content. ${ }^{41}$ The court held Prodigy Services Co. liable for defamation due to a defamatory statement posted by a user and entered a judgment against them of 200 million dollars. ${ }^{42}$

This judgment caught the attention of lawmakers who felt that legislation should be put in place that would allow ICS providers to remove content that was objectionable without facing liability as editors and publishers. ${ }^{43}$ Legislators feared that the precedent of Prodigy, which treated ICS providers as editors and publishers of third-party content, would not lead to more accurate and thorough screening of content online - but rather would lead to no screening at all. ${ }^{44}$ No screening or moderation of third-party Internet content at all would mean the Internet would be overflowing with exactly what Section 230 permits ICS providers to remove - "obscene, lewd, lascivious, filthy, excessively violent, harassing, or otherwise objectionable" content. ${ }^{45}$

Essentially, under Prodigy, ICS providers faced the moderator's dilemma - either try to moderate perfectly and risk liability or do no moderation at all and be free from liability. ${ }^{46}$ To avoid this dilemma, Section 230 of the Communications Decency Act was passed, and as the original drafters intended, ICS providers could now selectively

39. See Stratton Oakmont, Inc. v. Prodigy Servs. Co., No. 31063/94, 1995 WL 323710 at *7 (N.Y. Sup. Ct. May 24, 1995).

40. Id.

41. Id. at *3-4.

42. Danielle Keats Citron, Hate Crimes in Cyberspace 169 (2016).

43. Citron \& Wittes, supra note 27, at 405.

44. Id. (citing Citron, supra note 13, at 166 n.377).

45. U.S. Dep'T OF JUST., SeCtion 230 - NuRTURING InNOVATION OR FOSTERING UNACCOUNTABILITY? 21 (2020), https://www.justice.gov/file/1286331 /download [https://perma.cc/ZMK3-4QX6].

46. MARgARET Jackson \& MARita Shelly, Legal Regulations, IMPLICATIONS, AND ISSUES SURROUNDING DigitAL DATA 70 (2020). 
filter out content that they did not want on their sites without being liable for whatever else third parties posted to their sites. ${ }^{47}$

The protection given under Section 230 for "'Good Samaritan' blocking" was, in part, originally intended to encourage ICS providers to keep their platforms free of harmful content inappropriate for minors. ${ }^{48}$ Section 230 did more than enable ICS providers to keep their platforms free of undesirable content - it also ensured that the fledgling Internet companies of the late twentieth and early twenty-first centuries were not sued so much that they would cease to exist andperhaps - the Internet with them. ${ }^{49}$ This is still a vital function of Section 230 today as it allows for start-ups and new ICSs to develop without the threat of legal liability that could put them out of business. ${ }^{50}$

Just as it was intended to do, one year after its passage, in a seminal case, Section 230 effectively shielded AOL, an ICS provider, from intermediary liability in a lawsuit brought against it by Ken Zeran. ${ }^{51}$ Zeran brought suit against AOL on account of defamatory content posted on its site, but because of Section 230, AOL no longer had any secondary liability for defamatory content posted by a third party. ${ }^{52}$ Over time many cases followed this precedent, giving rise to the very broad protection from intermediary liability under Section $230 .{ }^{53}$ The "hyper-protective" broad protection for ICS providers we have today is perhaps too overbroad. ${ }^{54}$

Since its passage, feelings towards Section 230 and its impact on online freedom of speech have differed significantly and changed along the way. ${ }^{55}$ To be sure, this trend will continue as laws and

47. Id. (quoting JefF KossefF, The Twenty-Six Words That Created the INTERNET 60 (2019)).

48. Exec. Order No. 13925, 85 Fed. Reg. 34,079 (May 28, 2020).

49. JACKSON \& SHELlY, supra note 46, at 70 (quoting KOSSEFF, supra note 47, at 60$)$.

50. U.S. DEP'T OF JUST., supra note 45 , at 1.

51. Zeran v. Am. Online, Inc., 129 F.3d 327, 330 (4th Cir. 1997) (Section 230 "creates a federal immunity to any cause of action that would make service providers liable for information originating with a third-party user of the service."); see also JACKSON \& SHELLY, supra note 46, at 70.

52. Zeran, 129 F.3d at 330; see also JACKSON \& SHELLY, supra note 46, at 70.

53. Citron \& Wittes, supra note 27, at 409 (citing Ambika Doran \& Tom Wyrwich, Section 230 of the Communications Decency Act Turns 20, LAw360 (Sept. 7, 2016, 12:27 PM), https://www.law360.com/articles/836281/section-230-of-thecommunications-decency-act-turns-20 [https://perma.cc/QCU9-GEQ3]).

54. Id. at 403.

55. Jack M. Balkin, The Future of Free Expression in A Digital Age, 36 PEPP. L. REV. 427, 434 (2009); see also Balkin, supra note 6, at 1194, 1209; Bobby Allyn, 
precedents surrounding Section 230 and intermediary liability continue to develop and change.

\section{B. Problems Associated with Section 230}

Because Big Tech companies have a monopoly over certain types of services online, it is hard for users to stop using their services because there are no viable alternatives. ${ }^{56}$ This has led to vast numbers of users on platforms such as Facebook and Twitter - and yet, many are unhappy with the terms of service or how they are enforced. ${ }^{57}$ Many complain about over-moderation by ICS providers that target certain viewpoints and borders censorship. Still, others protest undermoderation because it leads to uncomely and even unsafe cyberspaces.

\section{Over-Moderation}

Because so much communication and public discourse takes place online by so many individuals and entities, ICSs have essentially become modern-day public squares (spheres of public opinion) - but in these public squares, there are private actors that have the power to determine what people can and cannot say. ${ }^{58}$ Section 230 allows ICS providers to block or remove third-party material "whether or not such material is constitutionally protected." ${ }^{59}$ ICS providers may choose to over-moderate by censoring content for a variety of reasons, and this leads to the loss of online freedom of speech for those whose speech is regulated or censored by non-elected ICS providers. ${ }^{60}$ If governments as elected representatives are prohibited from exercising such power over free speech, then un-elected private companies should

Justice Clarence Thomas Takes Aim at Tech and Its Power 'To Cut Off Speech,' NAT'L. PuB. RADiO (Apr. 5, 2021), https://www.npr.org/2021/04/05/984440891 /justice-clarence-thomas-takes-aims-at-tech-and-its-power-to-cut-off-speech [https: //perma.cc/59HX-HZDD].

56. Sarah Joseph, Why the Business Model of Social Media Giants Like Facebook is Incompatible with Human Rights, THE CONVERSATION (Apr. 2, 2018, 3:59 $\mathrm{PM}$ ), https://theconversation.com/why-the-business-model-of-social-media-giantslike-facebook-is-incompatible-with-human-rights-94016 [https://perma.cc/WB2B97F6]; see also MASNICK, supra note 14, at 29-29.

57. See MASNICK, supra note 14, at 7, 28-29.

58. Exec. Order No. 13925, 85 Fed. Reg. 34,079 (May 28, 2020).

59. 47 U.S.C. $\S 230(\mathrm{c})(2)(\mathrm{A})$.

60. Hannah Bloch-Wehba, Global Platform Governance: Private Power in the Shadow of the State, 72 SMU L. REV. 27, 61 (2019) (citing Kyle Langvardt, Regulating Online Content Moderation, 106 GEO. L.J. 1353, 1358 (2018)). 
certainly not have such absolute power. ${ }^{61}$ When freedom of speech is lost online, we also lose, to an extent, the valuable "public square" that the Internet can be when unfettered by censorship. ${ }^{62}$

In the United States, the values of the First Amendment are as important now as they ever have been. ${ }^{63}$ It is important to note that even though First Amendment protections apply only to actions by the state, there is still concern about the dramatic impact that private actors, such as social media sites, can have on the quantity and quality of free speech in the United States. "The Supreme Court has noted that social media sites ... 'can provide perhaps the most powerful mechanisms available to a private citizen to make his or her voice heard." 64 However, because of the freedom that ICS providers have to remove third-party content, some believe that Section 230 poses a serious threat to freedom of speech online. ${ }^{65}$ Even though the intent of Section 230 was to ensure "that companies that do some measure of blocking are immunized for what they miss in $\S 230(\mathrm{c})(1)$ and are immunized for the act of blocking itself in $\S 230(c)(2)$ "- - it is clear that the immunity is much broader and can even allow for over-moderation. ${ }^{66}$

\section{Under-Moderation}

Just as a gardener tends to a garden to control weeds and promote plant growth, under Section 230, ICS providers can and should tend to their "virtual gardens" by moderating and filtering the speech posted by third parties. ${ }^{67}$ Indeed, Section 230 was originally intended to encourage ICS providers to keep their platforms free of harmful content inappropriate for minors. ${ }^{68}$ ICS providers are free to moderate and remove third-party content. ICS providers can misuse this freedom to leave up or remove content.

61. See id.

62. Candeub, supra note 19 , at 429.

63. Balkin, supra note 55, at 427-28.

64. Exec. Order No. 13925, 85 Fed. Reg. 34,079 (May 28, 2020) (quoting Packingham v. North Carolina, 137 S. Ct. 1730, 1737 (2017)).

65. Id.

66. Citron \& Wittes, supra note 27, at 408.

67. Jess Miers, Section 230: What You Don't Know Might Destroy the Internet, YouTuBE: TEDx TALKS (Apr. 11, 2019), https://www.youtube.com/watch $? \mathrm{v}=7 \mathrm{EGRRM} \mathrm{kMac} \&$ feature=youtu.be\&t=585 [https://perma.cc/QH7V-XNBJ].

68. Exec. Örder No. 13925, 85 Fed. Reg. at 34,079. 
The development of case law around Section 230 has made it so that ICS providers are now broadly immunized from intermediary liability even when they have encouraged posting illegal content ${ }^{69}$ or enabled illegal activity by the way of their policies and website design. ${ }^{70}$ There have been hundreds of cases expanding the protection of Section 230 from intermediary liability for under-moderation and relatively very few minimizing it. ${ }^{71}$ Danielle Keats Citron and Benjamin Wittes put it well, saying that the "blanket immunity gives platforms a license to solicit illegal activity. ... Site operators have no reason to take down material that is clearly defamatory or invasive of privacy. They have no incentive to respond to clear instances of criminality or tortious behavior."72

It is important to understand that the broad immunity provided by Section 230 does have statutory exceptions (some existing from the time of Section 230's birth and others added later), including criminal law, intellectual property law, the Electronic Communications Privacy Act, state laws that are consistent with Section 230, and the Allow States and Victims to Fight Online Sex Trafficking Act ("FOSTA"). ${ }^{73}$ Despite these exceptions, the protection offered by Section 230 is still far-reaching.

\section{The Two Types of Propositions to “FiX” Section 230}

There are essentially two types of propositions to "fix" Section 230. The first group of propositions tries to either limit the type of content that ICS providers can take down or expand the type of content that ICS providers must take down. The second group of propositions focuses on making Section 230 more like a traditional common carriage arrangement by means of granting monopolies. ${ }^{74}$

69. Citron \& Wittes, supra note 27, at 408 (citing Shiamili v. Real Estate Grp. of N.Y., Inc., 952 N.E.2d 1011, 1019 (N.Y. 2011); Phan v. Pham, 105 Cal. Rptr. 3d 791, 795 (Cal. Ct. App. 2010)).

70. Citron \& Wittes, supra note 27 , at 408.

71. Id. at 409 (citing Ambika Doran \& Tom Wyrwich, Section 230 of the Communications Decency Act Turns 20, LAw360 (Sept. 7, 2016, 12:27 PM), https:/ /www.law360.com/articles/836281/section-230-of-the-communications-decencyact-turns-20 [https://perma.cc/QCU9-GEQ3]).

72. Id. at 414 .

73. JACKSON \& SHELLY, supra note 46, at 70-71.

74. Elliot Harmon, Don't Blame Section 230 for Big Tech's Failures. Blame Big Tech., EleC. FronTIER Found. (Nov. 16, 2020), https://www.eff.org/deeplinks /2020/11/dont-blame-section-230-big-techs-failures-blame-big-tech [https://perma 


\section{A. Stripping Section 230 Protections}

People across the political spectrum have gripes about Section 230. However, one side argues that Section 230 allows over-moderation and the other that Section 230 inhibits moderation and leads to under-moderation. ${ }^{75}$ Both President Joe Biden and President Donald Trump have called to repeal Section $230 .{ }^{76}$ There have also been many calls to reform Section 230 significantly. ${ }^{77}$

\section{Executive Order on Preventing Online Censorship}

Because of the position that Section 230 allows over-moderation, there are propositions to limit the amount of moderation that ICS providers are allowed to do. For example, President Trump recently issued the Executive Order on Preventing Online Censorship, which addresses issues with Section 230 and argues that the law should not grant ICS providers immunity when they choose to restrict access to content that does not live up to the standard of "obscene, lewd, lascivious, filthy, excessively violent, harassing, or otherwise objectionable." "78 The problem is that "otherwise objectionable" is a broad catchall phrase that Congress has yet to clarify. ${ }^{79}$ It has proven to be a very low threshold, and changing that threshold would alter Section 230 drastically.

The Trump Executive Order calls for narrowing the content ICS providers can remove without liability, citing that the original purpose

.cc/555G-YPW2].

75. Zhanna Malekos Smith, The Goldilocks Porridge Problem with Section 230, CTR. FOR STRATEGIC AND INT'L STUD. (Nov. 3, 2020), https://www.csis.org/blogs /technology-policy-blog/goldilocks-porridge-problem-section-230 [https://perma .cc/BG78-92F4].

76. Id.; see also Anshu Siripurapu, Trump and Section 230: What to Know, COUNCIL ON FOREIGN RELS. (last updated Dec. 2, 2020, 7:00 AM), https://www.cfr .org/in-brief/trump-and-section-230-what-know [https://perma.cc/2TSZ-B33N].

77. Casey Newton, Everything You Need to Know About Section 230, THE VERGE (Dec. 9, 2020, 4:50 PM), https://www.theverge.com/21273768/section-230explained-internet-speech-law-definition-guide-free-moderation [https://perma.cc /3SE8-4NYF].

78. 47 U.S.C. § 230; Exec. Order No. 13925, 85 Fed. Reg. 34,079 (May 28, 2020).

79. James Kachmar, Is Your Competitor Objectionable? The Scope of Immunity Under the Communications Decency Act, WeINTRAUB TOBIN (Jan. 23, 2020), https: //www.theiplawblog.com/2020/01/articles/ip/is-your-competitor-objectionable-thescope-of-immunity-under-the-communications-decency-act/ [https://perma.cc /VY23-KUGD]. 
of the "'Good Samaritan' blocking" protection under Section 230 was to encourage ICS providers to keep their platforms free of harmful content inappropriate for minors. ${ }^{80}$ It also suggests that the "good faith" requirement under Section 230(c)(2)(a) should be a much higher standard that must be met in order for ICS providers to qualify for immunity from actions brought against them on account of restricting access to material. ${ }^{81}$ These regulatory changes would change the way ICS providers moderate but would not necessarily be the best thing to fix moderation issues and protect freedom of speech online. ${ }^{82}$ As has been shown by recent events, ICS providers do not need to remove content to silence voices online because they can simply disable a user's account for posting or even ban a person from their platform. ${ }^{83}$ The changes made under the Trump Executive Order might prohibit ICS providers from blocking or banning users, but this would simply exacerbate issues associated with under-moderation as outlined below.

According to President Trump, when ICS providers censor content that they do not agree with, they are no longer passive facilitators of online communication but rather online publishers and editors as they were before the passage of Section $230 .{ }^{84}$ This approach might lead to a situation that mirrors the state of the law as it was under Prodigy - either try to moderate perfectly and risk liability, or do no moderation at all and be free from liability. Many people who are

80. Exec. Order No. 13925, 85 Fed. Reg. at 34,079; see also Hoeg Law, Section 230 Executive Order SIGNED! A Lawyer Re-Reviews Trump's Plan (VL238), YouTuBE (May. 28, 2020), https://www.youtube.com/watch $? \mathrm{v}=$ gmBGFVUjCaI\&t=631s [https://perma.cc/E3W7-4K6C].

81. Exec. Order No. 13925, 85 Fed. Reg. at 34,079; see also Hoeg Law, Section 230 Executive Order SIGNED! A Lawyer Re-Reviews Trump's Plan (VL238), YouTube (May. 28, 2020), https://www.youtube.com/watch ?v=gmBGFVUjCaI\&t=631s [https://perma.cc/E3W7-4K6C].

82. Elliot Harmon, Don't Blame Section 230 for Big Tech's Failures. Blame Big Tech., ElEC. FrontiER Found. (Nov. 16, 2020), https://www.eff.org/deeplinks /2020/11/dont-blame-section-230-big-techs-failures-blame-big-tech [https://perma .cc/555G-YPW2].

83. See Permanent suspension of @realDonaldTrump, TwITTER INC. (Jan. 8, 2021), https://blog.twitter.com/en_us/topics/company/2020/suspension [https:/ /perma.cc/8W5B-2X6G].

84. Exec. Order No. 13925, 85 Fed. Reg. at 34,079. The Trump Executive Order might lead to a situation mirroring the state of the law under Prodigy - either try to moderate perfectly and risk liability or do no moderation at all and be free from liability. However, Section 230 was passed to give ICS providers freedom to moderate as they see fit in order to create and curate internet spaces according to their own taste. 
advocating for less content moderation and freedom of speech online or who are criticizing existing law in order to fix content moderation and promote free speech online are going about it in the wrong way. ${ }^{85}$

The Trump Executive Order calls to stop much of the moderation that takes place online, and, in President Trump's view, it would lead to more speech and thus protect freedom of speech online. ${ }^{86}$ However, more speech is not always better. ${ }^{87}$ Speech is protected because it is vital to the democratic process and to the marketplace of ideas, "but false speech can infect that marketplace and there is no reason to believe that truth will triumph ... and it is fanciful to think that more speech necessarily can undo the harms." 88

ICSs today use automated moderation via software as well as human moderators who both act on content that users flag. ${ }^{89}$ The Trump Executive Order could restrict a lot of the content moderation that is based on users flagging objectionable content or content that has not been flagged but is simply objectionable. Examples of such content are "nudity or pornography, insults or attacks based on religion, ethnicity, or sexual orientation, inappropriate or annoying content, content that is humiliating, or content that advocates violence to a person or animal." 90 This would result in uncomely and unwelcoming internet spaces.

\section{The Stop the Censorship Act}

The Stop the Censorship Act (the "Act") also tries to narrow the content that ICS providers are allowed to remove without facing intermediary liability, and, because of this, it presents some of the same issues that the Trump Executive Order does. ${ }^{91}$ The Act, introduced to the House of Representatives on July 25, 2019, suggests changing the

85. Elliot Harmon, Don't Blame Section 230 for Big Tech's Failures. Blame Big Tech., ElEC. FRONTIER FOUND. (Nov. 16, 2020), https://www.eff.org/deeplinks /2020/11/dont-blame-section-230-big-techs-failures-blame-big-tech [https://perma .cc/555G-YPW2].

86. Exec. Order No. 13925, 85 Fed. Reg. at 34,079.

87. Erwin Chemerinsky, False Speech and the First Amendment, 71 OKLA. L. REV. 1, 9 (2018).

88. Id.

89. Kate Klonick, The New Governors: The People, Rules, and Processes Governing Online Speech, 131 HARV. L. REV. 1598, 1637 (2018).

90. Id. at 1640.

91. Stop the Censorship Act, H.R. 4027, 116th Cong. (2019). 
current language found in Section 230(c)(2)(A). ${ }^{92}$ Currently, Section 230 allows any good faith action by ICS providers to restrict access to or availability of "material that the provider or user considers to be obscene, lewd, lascivious, filthy, excessively violent, harassing, or otherwise objectionable." "93 The change proposed would only allow ICS providers to restrict access to or availability of "unlawful material." 94

This change in language would prohibit ICS providers from blocking "obscene, lewd, lascivious, filthy, excessively violent, harassing, or otherwise objectionable content," 95 like spam or malware because they are not illegal. ${ }^{96}$ It would also prohibit the removal of "nudity or pornography, insults or attacks based on religion, ethnicity, or sexual orientation, inappropriate or annoying content, content that is humiliating, or content that advocates violence to a person or animal" as long as it is not illegal. ${ }^{97}$ Eric Goldman has said that this Act should be properly named the "Censorship Act." volves around the fact that the Act would allow "spam, spyware, malware, and viruses" to go unmoderated..$^{99}$ Further, he states that if ICS providers were to actually change the way they moderate content due to the Act, "they would be overrun by trollers, spammers, and miscreants, which would crowd out all productive conversations." 100

However, the proposed bill also seeks to create a new way for ICS providers to moderate and filter content by allowing users to choose filters that are personalized. ${ }^{101}$ Allowing ICS providers to take any action "to provide users with the option to restrict access to any other

92. $I d$.

93. Id.

94. $I d$.

95. Id.

96. Mark Rasch, Can Antivirus Companies Use 'Good Samaritan'Defense to Block Rival Software?, SEC. BoulevarD (Dec. 6, 2019), https://securityboulevard .com/2019/12/can-antivirus-companies-use-good-samaritan-defense-to-block-rival -software/ [https://perma.cc/H3JM-RD2H].

97. See Stop the Censorship Act, H.R. 4027, 116th Cong. (2019); Klonick, supra note 89 , at 1640 .

98. Eric Goldman, Comments on Rep. Gosar's "Stop the Censorship Act," Another "Conservative" Attack on Section 230, TECH. \& MKTG. L. BloG (Apr. 15, 2019), https://blog.ericgoldman.org/archives/2019/08/comments-on-rep-gosarsstop-the-censorship-act-another-conservative-attack-on-section-230.htm [https:/ /perma.cc/8VTR-UDTD].

99. Id.

100. Id.

101. Stop the Censorship Act, H.R. 4027, 116th Cong. (2019). 
material, whether or not such material is constitutionally protected" would accomplish this goal. ${ }^{102}$ The Act would permit each individual (not the platform) to choose their own algorithm or filter. ${ }^{103}$ Even with such filtering in place, the Act, like the Trump Executive Order, falls short of "fixing" the Internet's Section 230 woes, but perhaps for a different reason-it still leaves Big Tech platforms with too much power. The Act would do nothing to curtail the dominance of Big Tech platforms and foster competition. Further, under the Act, Big Tech platforms would have the discretion to create only certain filter options for users to pick from, and there would certainly be people unsatisfied with the filter options presented and the effects they would have on content moderation. ${ }^{104}$

\section{Reform May Increase Private Governance}

Because so much power resides in the privately-owned platforms' infrastructures, they can be used to govern speech online via content moderation. These infrastructures allow policies to be implemented at the "click of a button" can often be abused not only by those who own them but by government actors seeking to co-opt their power. ${ }^{105}$

Because some believe that Section 230 inhibits moderation and leads to under-moderation, they believe that the government should take a more active role in determining what content ICS providers should remove. ${ }^{106}$ Because ICS user bases rival the size of large countries, their terms of service and content moderation decisions begin to seem a lot like government action. ${ }^{107}$ Indeed, sometimes, because of private governance, this can actually be the case. Private governance in the context of the Internet and ICS providers refers to the cooperation of ICS providers with governments and the government co-optation of ICS providers' infrastructure to exercise control over nation-

102. Id.

103. See id.

104. See generally Elliot Harmon, Don't Blame Section 230 for Big Tech's Failures. Blame Big Tech., ELEC. FronTIER Found. (Nov. 16, 2020), https://www.eff .org/deeplinks/2020/11/dont-blame-section-230-big-techs-failures-blame-big-tech [https://perma.cc/555G-YPW2].

105. See Balkin, supra note 3, at 2017.

106. Zhanna Malekos Smith, The Goldilocks Porridge Problem with Section 230, CTR. FOR STRATEGIC AND INT'L STUD. (Nov. 3, 2020), https://www.csis.org/blogs /technology-policy-blog/goldilocks-porridge-problem-section-230 [https://perma .cc/BG78-92F4].

107. See Balkin, supra note 3, at 2021. 
states by implementing and enforcing laws via the ICS providers' infrastructure. "Cooperation and co-optation are particularly concerning where they slide into 'soft censorship' or 'jawboning' by persuading or pressuring platforms to adopt government's favored limitations on speech, because they limit the ability of the public to hold the government accountable for those limitations." 108 When the power to govern online is so centralized in platforms, they are more susceptible to governments approaching them and telling them to "locate and block or censor [a user], or else we will punish or fine you."109 These decisions are often opaque and made under the guise of ever-changing terms of service. ${ }^{110}$ Even when not influenced by government action, ICS providers govern their platforms, but it is not a good idea to hold them to government standards, such as the First Amendment. ${ }^{111}$

Mirko Hohmann and Alexander Pirang of the Global Public Policy Institute in Berlin point out that "setting the rules of the digital public square, including the identification of what is lawful and what is not, should not be left to private companies." 112 Likewise, private companies should neither moderate nor censor under the guise of their own terms of service when, in reality, they are carrying out governmental orders. Essentially, private governance comingles nation-state and private powers and allows governments to avoid responsibility for actions carried out via private governance. ${ }^{113}$ To better understand what private governance looks like, it is helpful to look at some European Union ("EU”) laws.

In the EU, national governments, such as Germany, are now beginning to require the removal of illegal content or sometimes even legal content that is simply offensive. ${ }^{114}$ This is a prime example of a

108. Bloch-Wehba, supra note 60 , at 63.

109. Balkin, supra note 3 , at 2017.

110. Hannah Bloch-Wehba, Automation in Moderation, 53 CoRnEll INT'L L.J. 41, 78 (2020).

111. Balkin, supra note 3, at 2026 ("Even so, it is generally a bad idea to hold social media spaces to the same standards as municipal governments under the First Amendment. Imposing the same First Amendment doctrines that apply to municipalities to social media companies would quickly make these spaces far less valuable to end users, if not wholly ungovernable.").

112. Melissa Eddy \& Mark Scott, Delete Hate Speech or Pay Up, Germany Tells Social Media Companies, N.Y. TIMES (June 30, 2017), https://www.nytimes.com /2017/06/30/business/germany-facebook-google-twitter.html [https://perma.cc /EJW3-BNNB].

113. Bloch-Wehba, supra note 60 , at 30.

114. Brian Chang, From Internet Referral Units to International Agreements: 
piece of legislation that, if enacted in the United States, would weaken Section 230 by expanding the type of content that ICS providers must take down. This legislation in Germany is known as NetzDG, and some believe that the government designed it to co-opt ICS providers into enforcing legal standards and policies. ${ }^{115}$ The law requires providers of social networks (ICS providers) "to maintain an effective and transparent procedure for handling complaints about unlawful content." 116 Upon receiving a complaint, the ICS provider must "remove[] or block[] access to content that is manifestly unlawful within 24 hours of receiving the complaint," and all other unlawful content must be removed or blocked "immediately, this generally being within 7 days of receiving the complaint." 117 The government may fine ICS providers that do not comply by taking down potentially illegal, racist, or slanderous content up to $\$ 57$ million. ${ }^{118}$ Again, this can lead to overmoderation, and "speakers get no judicial determination of whether their speech is legally protected or unprotected."119

The main problem evident in the EU's approach to intermediary liability and the United States' approach that calls for more government-mandated moderation is that it could lead to over-moderation. ${ }^{120}$ A law that requires ICS providers to make quick and precise legal judgments will likely cause ICS providers to err on the side of caution by granting take-down requests that may have little or no merit. ${ }^{121}$ This is because ICS providers need to be sure they do not leave up content that could result in a fine if they make the wrong decision. ${ }^{122}$ The

Censorship of the Internet by the UK and EU, 49 COLUM. HUM. RTS. L. REV. 114, 118 (2018).

115. Balkin, supra note 3, at 2030.

116. Netzdurchsetzunggesetz [NetzDG] [Network Enforcement Act], Oct. 1, 2017, Bundesgesetzblatt [BGBI] at 612017 VI p. 3352, § 3(1) (Ger.). See also Network Enforcement Act (Netzdurchsetzunggesetz, [NetzDG]), Ger. L. Archive (Jan. 26, 2018), https://germanlawarchive.iuscomp.org/?p=1245 [https://perma.cc/4UQU $-\mathrm{E} 87 \mathrm{~T}]$

117. Id. at $\S 3(2)$, para. 2-3.

118. Melissa Eddy \& Mark Scott, Delete Hate Speech or Pay Up, Germany Tells Social Media Companies, N.Y. TIMES (June 30, 2017), https://www.nytimes.com /2017/06/30/business/germany-facebook-google-twitter.html [https://perma.cc /EJW3-BNNB].

119. Balkin, supra note 3, at 2031.

120. Id. at $2017-18$.

121. Id.; see Annemarie Bridy, Remediating Social Media: A Layer-Conscious Approach, 24 B.U. J. SCI. \& TECH. L. 193, 225 (2018).

122. Balkin, supra note 3, at 2013, 2018; Melissa Eddy \& Mark Scott, Delete Hate Speech or Pay Up, Germany Tells Social Media Companies, N.Y. TIMES (June 
resources and time needed to make an accurate legal determination for each complaint are great. Thus, ICS providers might wisely choose to not spend the time and resources to try to make the correct legal determination and instead just grant the requests. ${ }^{123}$ Thus, the choice to employ strict laws that hold ICS providers liable for certain third-party content may lead to more over-moderation, ${ }^{124}$ much like the Trump Executive Order and the Stop the Censorship Act.

In the EU, there have been some calls for reform of intermediary liability law. In contrast to the United States, where the law seeks to shield ICS providers, in the EU, "there has already been significant movement at the level of member states," where the states have moved towards punishing ICS providers rather than protecting them. ${ }^{125} \mathrm{EU}$ Justice Commissioner Vera Jourová said that she is not yet ready to propose EU-wide legislation, but she has stated that measures will need to be taken if individual member states do not self-regulate as Germany has. ${ }^{126}$

\section{B. Making Section 230 Operate Like Common Carriage}

Some are proponents of making Section 230 more like traditional common carriage arrangements by granting monopolies to ICS providers and imposing more liability on them. ${ }^{127}$ Some politicians have proposed making social media a public utility. ${ }^{128}$ In the past, when it did not make sense logistically (because of limited bandwidth) to have many small communications firms, the United States government struck "regulatory deals" with certain firms that made them legal

30, 2017), https://www.nytimes.com/2017/06/30/business/germany-facebookgoogle-twitter.html [https://perma.cc/EJW3-BNNB].

123. See Balkin, supra note 3, at 2018-19.

124. Id. at 2018-19, 2027.

125. David Morar \& Bruna Martins dos Santos, Online Content Moderation Lessons from Outside the US, BROOKINGS (June 17, 2020), https://www.brookings.edu /blog/techtank/2020/06/17/online-content-moderation-lessons-from-outside-the-u-s / [https://perma.cc/4D73-UM7X].

126. Chang, supra note 114, at 118.

127. Elliot Harmon, Don't Blame Section 230 for Big Tech's Failures. Blame Big Tech., ElEC. FrontiER Found. (Nov. 16, 2020), https://www.eff.org/deeplinks /2020/11/dont-blame-section-230-big-techs-failures-blame-big-tech [https://perma .cc/555G-YPW2].

128. See Elizabeth Warren, Here's How We Can Break Up Big Tech, Medium (Mar. 8, 2019), https://medium.com/@teamwarren/heres-how-we-can-break-up-big -tech-9ad9e0da324c [https://perma.cc/HFE6-2JF7]. 
monopolies. ${ }^{129}$ The government was willing to make exemptions to laws against monopolies because the firms agreed to terms that would benefit society. ${ }^{130}$ These terms that the firms committed to in return for the government-granted monopolies often included adopting nondiscriminatory policies, servicing unprofitable markets, and taking on extra liability. ${ }^{131}$ Adam Candeub points out that "Unlike telegraph and telephone companies, Facebook and Google to this day have no obligations to refrain from discrimination, carry all lawful messages, or provide any public good - even though they function as the dominant communications of their time." "132 However, companies like Facebook and Google should not be empowered to become "common carriage" monopolies.

Section 230 does look a lot like a "regulatory deal" where ICS providers are given a big legal break because they do not face secondary liability for third-party content even though they moderate some of that content. ${ }^{133}$ However, Section 230 places no commitment on ICS providers - they do not have to do anything to "earn" Section 230 's protections, ${ }^{134}$ and that is how it should stay. ICSs should not become common carriage arrangements or public utilities because Section 230 is not amenable to common carriage arrangements and there are other ways to "regulate around" content moderation issues online. ${ }^{135}$ Even though Section 230's "Good Samaritan provision is not quite the antithesis of a must-carry rule, it is a rather broad license to engage in the kind of content-based discrimination that is prohibited of common carriers," "136 thus making Section 230 not very amenable to common carriage adaptations at all. Supporters of common carriage online "and 'platform neutrality' appeal to notions of regulatory equity and symmetry." "137 They argue that what may be good at a network provider level is good at the ICS provider level. ${ }^{138}$ But "they fail to recognize ... that personalization-i.e., content discrimination-is

129. Candeub, supra note 19, at 407.

130. Id.

131. Id. at $396,408,412-13$.

132. Id. at 422 .

133. Id.

134. Id.

135. See generally MASNICK, supra note 14.

136. Bridy, supra note 121, at 209.

137. Id. at 227.

138. Id. 
central, not merely incidental, to the design of social media platforms." ${ }^{139}$ Further, these ICS monopolies have not formed with government authorization or intervention, but rather they have naturally formed due to the network effect. ${ }^{140}$

If the United States government made a "regulatory deal" with ICS providers and created an artificial monopoly, it could potentially stifle the free flow of ideas and innovation online. This is based on the idea that the "regulatory deal" would impose anti-discrimination standards on ICS providers, and, as Eric Goldman has argued, with every legislative "reigning in" of Section 230's broad-reaching immunity, Section 230 loses its power to protect freedom of expression online. ${ }^{141}$ Further, because monopolies are anti-competitive by definition, this arrangement would not allow for competitors to innovate and offer better social platforms. Additionally, a "regulatory deal" in the form of common carriage obligations for Big Tech would give even more power to the already too-powerful Big Tech companies. It would also put the government and Big Tech in a dangerously close relationship that could lead to abuses, like private governance, as discussed in the previous section. ${ }^{142}$

\section{SECTION 230 Is Not THE PROBLEM}

\section{A. What is Good About Section 230?}

Though there are problems with content moderation and free speech online, repealing or drastically changing Section 230 is not the solution to those problems. In fact, Section 230 actually bolsters the freedom of speech protections given by the First Amendment and adds procedural, as well as substantive, benefits to the freedom of speech protections provided by the First Amendment. ${ }^{143}$

First, Section 230 is a procedural tool that allows courts to dismiss lawsuits early on, avoiding costly First Amendment litigation because the prima facie case for Section 230 is much easier to prove than a

139. Id.

140. Candeub, supra note 19, at 422; Yun, supra note 21, at 314-17.

141. Eric Goldman, Why Section 230 Is Better Than the First Amendment, 95

Notre Dame L. ReV. ReFLeCtion 33, 34 (2019).

142. See generally Bloch-Wehba, supra note 60, at 30, 63 .

143. Goldman, supra note 141, at 34. 
prima facie case for the First Amendment. ${ }^{144}$ Section 230 does not harm free speech-it enhances it. It allows ICS providers to not be overly wary of what might happen to them if they do not control what third-parties post on their sites and that allows more speech to be posted. ${ }^{145}$ If Section 230 gets repealed, it is very uncertain how courts would interpret the First Amendment under facts that would have been easily and quickly dismissed under Section $230 .{ }^{146}$

Critics of Section 230, such as President Trump, point to the Big Tech companies like Facebook and Twitter as examples of what is wrong with Section 230. Big Tech moderates the content posted to their sites based on their own terms of service and relevant laws. Big Tech has a lot of resources to overcome whatever obstacles are put in their way. A repeal or rethinking of Section 230 might just cement Big Tech even more in their position of power because the protection offered by Section 230 actually ensures that start-up ICS companies are not sued so much that they go out of business. ${ }^{147}$

The main problem evident in taking immunity away from ICS providers is that, in order to comply with the law, ICS providers will likely err on the side of caution and grant take-down requests that may have little or no merit, leading to less speech. ${ }^{148}$ On the other hand, it may make the internet a place teeming with "trollers, spammers, and miscreants" whose speech drowns out the free speech of others. ${ }^{149} \mathrm{Ei}$ ther way, these content moderation issues lead to less free speech online if handled incorrectly. Section 230, as it is, promotes competition among ICSs. Because all ICS providers receive its protection, even small start-ups benefit from the protections that keep them out of lawsuits that could make them go out of business. ${ }^{150}$ Reigning in

144. Id. at 35 .

145. $I d$.

146. Anshu Siripurapu, Trump and Section 230: What to Know, CounCIL ON FOREIGN RELS. (last updated Dec. 2, 2020, 7:00 AM), https://www.cfr.org/in-brief /trump-and-section-230-what-know [https://perma.cc/2TSZ-B33N].

147. JACKSON \& SHELLY, supra note 46, at 70 (quoting KOSSEFF, supra note 47, at 60); see also Harmon, supra note 74.

148. See Bridy, supra note 121, at 225.

149. Goldman, supra note 98.

150. Jennifer Huddleston, Section 230 as a Pro-Competition Policy, Am. ACTION F. (Oct. 27, 2020), https://www.americanactionforum.org/insight/section-230-as-apro-competition-policy/ [https://perma.cc/A24P-XPYS]. 
Section 230 could stifle the competition that comes from smaller and newer ICS providers. ${ }^{151}$

\section{B. How to "Fix" Section 230 Without Changing or Weakening It}

Efforts would be better spent trying to allow for more competition amongst ICS providers. ICS providers like Facebook, Google, and Twitter require the attention of many users to be able to compete and dominate the market. ${ }^{152}$ To be able to avoid the issues of over-moderation, under-moderation, and private governance, users of ICSs should have more options. There should be more competition that drives ICS providers to use moderate content in ways that users approve of - this is actually what Section 230 was meant for. ${ }^{153}$

The amount of power that ICS providers like Facebook and Twitter have is astounding, bordering on monopolistic control. ${ }^{154}$ Instead of focusing on the perceived shortcomings of Section 230, reform should focus on what Section 230 does well and, in turn, focus on different solutions to resolve free speech problems online. Because calls for Section 230 reform come for different reasons from either side of the political spectrum, ${ }^{155}$ it is important that the solution is comprehensive in addressing content moderation and free speech problems online. If politicians' constituencies were happy with content moderation online, there would not be so much political uproar and commentary about Section $230 .{ }^{156}$ So, to fix the problem, instead of reforming or repealing Section 230, it should be left as it is, and the focus should be on fighting the monopolistic nature of Big Tech companies with antitrust law and fostering competition amongst ICSs. Antitrust action along with fundamental changes to ICSs' digital infrastructures could solve many content-moderation and free speech issues online.

151. Id.

152. Keith N. Hylton, Digital Platforms and Antitrust Law, 98 NEB. L. REV. 272, 273 (2019).

153. Citron \& Wittes, supra note 27, at 404

154. Kenneth Rogoff, Big Tech Has Too Much Monopoly Power - It's Right To Take It On, GUARDIAN (Apr. 2, 2019), https://www.theguardian.com/technology /2019/apr/02/big-tech-monopoly-power-elizabeth-warren-technology [https:/ /perma.cc/Y9K8-DBTB].

155. Zhanna Malekos Smith, The Goldilocks Porridge Problem with Section 230, CTR. FOR STRATEGIC AND INT'L STUD. (Nov. 3, 2020), https://www.csis.org/blogs /technology-policy-blog/goldilocks-porridge-problem-section-230 [https://perma .cc/BG78-92F4].

156. Id. 
Antitrust action by the government could be successful in limiting anticompetitive acquisitions and providing more competition, diversity, and innovation, leading to more ICS companies instead of only a few massive ones. ${ }^{157}$ However, there are some who question whether existing antitrust law would work for ICSs. ${ }^{158}$ Even if existing antitrust laws worked to perfection, it would still mean losing the value of big ICSs' networks and the network effects. Further, breaking up Big Tech ICSs does not guarantee that content moderation practices affecting free speech online would never arise again. ${ }^{159}$ Companies like Google, Facebook, and Twitter are not like traditional monopolies that gain $100 \%$ market control and then raise prices. ${ }^{160}$ In fact, these companies often do not charge anything for their "services" and instead collect data about their users to sell targeted advertising to third parties. ${ }^{161}$ There are many concerns about Big Tech's consumer privacy practices, in addition to concerns about content moderation and free speech online. ${ }^{162}$ So, breaking up companies like Facebook or Google that are not committing traditional monopoly offenses would not necessarily do away with consumer privacy concerns or content moderation and free speech issues online. ${ }^{163}$ It may make the problems go away temporarily, just for them to surface again later on new platforms.

Mike Masnick in his 2019 article suggested a novel solution to cure the ills plaguing content moderation and free speech online that could work in conjunction with antitrust measures or even on its

157. Yun, supra note 21, at 355-56; see generally Hylton, supra note 152.

158. Kyle Langvardt, Regulating Online Content Moderation, 106 GEO. L.J. 1353, 1372 (2018); see also Tyler Cowen, Breaking Up Facebook Would Be a Big Mistake, SLATE (June 13, 2019), https://slate.com/technology/2019/06/facebook-big -tech-antitrust-breakup-mistake.html [https://perma.cc/CXS6-9HWE].

159. Jennifer Huddleston, Section 230 as a Pro-Competition Policy, AM. ACTION F. (Oct. 27, 2020), https://www.americanactionforum.org/insight/section-230-as-apro-competition-policy/ [https://perma.cc/A24P-XPYS].

160. Tyler Cowen, Breaking Up Facebook Would Be a Big Mistake, SLATE (June 13, 2019), https://slate.com/technology/2019/06/facebook-big-tech-antitrustbreakup-mistake.html [https://perma.cc/CXS6-9HWE].

161. Balkin, supra note 6, at 1192.

162. Bloch-Wehba, supra note 60, at 43.

163. Jennifer Huddleston, Section 230 as a Pro-Competition Policy, Am. ACTION F. (Oct. 27, 2020), https://www.americanactionforum.org/insight/section-230-as-apro-competition-policy/ [https://perma.cc/A24P-XPYS]; Tyler Cowen, Breaking Up Facebook Would Be a Big Mistake, SlATE (June 13, 2019), https://slate.com /technology/2019/06/facebook-big-tech-antitrust-breakup-mistake.html [https:/ /perma.cc/CXS6-9HWE]. 
own. ${ }^{164}$ His solution: "[B]uild protocols not platforms."165 In years past, the internet operated using many different protocols. ${ }^{166}$ One that still prevails today is Simple Mail Transfer Protocol ("SMTP"), which is used for email. ${ }^{167}$ Have you ever wondered why you can email someone who uses a different email service without any issues, and all the while it is not possible to message someone on Twitter via Facebook? Essentially it is because Facebook and Twitter are privately owned platforms and not public protocols. ${ }^{168}$

Protocols would offer many advantages that platforms do not offer. ${ }^{169}$ Take Twitter, for example. Twitter is one-of-a-kind, and there are no other services with the size and popularity of Twitter that behave exactly like Twitter does. However, recently, an ICS provider whose platform was very similar to Twitter, called Parler, somewhat anticipated that many users of the most prevalent ICSs would be unsatisfied with the moderation on those platforms. To this end, in 2018, Parler was launched and marketed as "Twitter" without the "censorship." 170 It boasted many of the same features as Twitter, but because of perceived unfairness in moderation towards conservatives, many people dissatisfied with Twitter opened Parler accounts. ${ }^{171}$ Most of those accounts opened in the days and weeks surrounding the 2020 presidential election. ${ }^{172}$

Soon after the election, Google, Apple, and Amazon put an end to Parler's short lived surge of popularity by removing it from the Google and Apple app stores and booting it off of Amazon Web Services. ${ }^{173}$ Google and Apple suspended Parler from their respective app stores because Parler was "allowing too many [posts] that encouraged violence and crime." ${ }^{174}$ While Amazon removed Parler from its web

164. See MASNICK, supra note 14 .

165. Id.

166. Id.

167. $I d$.

168. Id.

169. Id.

170. Jack Nicas and Davey Alba, Amazon, Apple and Google Cut Off Parler, an App That Drew Trump Supporters, N. Y. TIMES (last updated Jan. 13, 2021), https:/ /www.nytimes.com/2021/01/09/technology/apple-google-parler.html [https:/ /perma.cc/44FH-78V7].

171. Id.

172. See id.

173. Id.

174. Id. 
services because it "repeated[ly] violat[ed] . . . Amazon's rules."175 Parler demonstrated the many problems with extremely lax moderation standards, and this caused its demise. ${ }^{176}$ Clearly, both over-moderation and under-moderation affect free speech online. So, what will it take to arrive at the perfect balance? Perhaps antitrust law alone could resolve these issues, ${ }^{177}$ but in breaking up Big Tech's ICSs, the value of their massive networks is lost. A significant change to the digital infrastructure of the internet could be just as effective and even work in conjunction with antitrust law to conserve the valuable network effects.

In the case of Parler and Twitter, both are privately owned infrastructures or platforms. So, with protocols, "rather than relying on a few giant platforms to police speech online, there could be widespread competition, in which anyone could design their own interfaces, filters, and additional services, allowing whichever ones work best to succeed, without having to resort to outright censorship for certain voices." 178 Using protocols widely would mean that services of the same protocol would be compatible with others of the same protocol but with unique filters and features. ${ }^{179}$ For example, Gmail and Protonmail offer different features, but at their core, they are both email services that are interoperable. ${ }^{180}$ Protocols allow ICSs to offer the advantages of network effects by allowing access to big networks because services that operate on the same protocol are interoperable and no implementation of a protocol would be isolated to only its own users. ${ }^{181}$ A shift to "social media protocols" could drive innovation for healthy content moderation practices and promote competition to create the service with the best content moderation online. ${ }^{182}$

Further, the resurgence of protocols on the internet could "allow end users to determine their own tolerances for different types of speech but make it much easier for most people to avoid the most

175. Id.

176. See id.

177. See generally Hylton, supra note 152.

178. MASNICK, supra note 14.

179. Id.

180. See John Faulds, Protonmail vs Gmail: What's the Best Email Provider for Your Business?, TECHRADAR (Sept. 4, 2020), https://www.techradar.com/news/protonmail-vs-gmail-whats-the-best-email-provider-for-your-business [https://perma .cc/QY5V-6ZHM].

181. See MASNICK, supra note 14.

182. See id. 
problematic speech, without silencing anyone entirely or having the platforms themselves make the decisions about who is allowed to speak." 183 The essence of the problem with content moderation and free speech online is that any decision made by a platform is going to upset someone. Platforms have two choices: remove disputed content and make someone angry, or do not remove disputed content and make someone else angry. ${ }^{184}$ For whatever reason it may be that a user of an ICS is angry, they often have no other meaningful alternative to the platform. ${ }^{185}$ For example, because of Facebook's dominant market position, "the extent that users feel beholden to Facebook . . . is not because the company offers them especially skillful services or judgments so much as because of a lack of viable alternatives."186 Meaning, a user who walks away from Facebook loses the entire Facebook network and cannot easily replace it with another service.

For example, referring back to the email example referenced above, if an email service fails or a user wishes to find a different service, there is an underlying email protocol that a new email service could be built on with relative speed and ease. This new email service could offer some of the same features and benefits of its failed predecessor while also offering improvements. Because it would be built on the same protocol as other email services, it would be interoperable with all other email service implementations. This would make it relatively easy for users to move to the new service and retain the benefits of the network effects.

Because Twitter and Parler are each separate platforms not based on a common protocol, when the Twitter wannabe, Parler, failed, there were no like alternatives to Parler. If there had been an underlying "Twitter protocol," there would have already been many "Twitter protocol implementations" long before January 6, 2021. This would have allowed users to choose whatever implementation of the "Twitter protocol" they preferred. That implementation would offer them content moderation practices that they agreed with while giving them access to the entire user base of the "Twitter protocol." Had this been the case, the content moderation preferences of many of those who left

183. Id.

184. Id.

185. See id.

186. Lina M. Khan \& David E. Pozen, A Skeptical View of Information Fiduciaries, 133 HARV. L. REV. 497, 518 (2019). 
Twitter for Parler would have been available and the need for a wellpoliced ICS mostly free of violence and crime would have been met. The key is that, in an online world dominated by protocols, there would be an array of protocols modeling the many types of platforms that now exist, but there would be "many competing interface implementations" built on each protocol to satisfy many different preferences and needs. ${ }^{187}$

Building on top of the already existing protocols would be faster and easier than building an entirely new Facebook or Twitter. ${ }^{188}$ It would allow for access to the entire user base of any given protocol and make switching between interface implementations built on the same protocol relatively easy. ${ }^{189}$ The result is a competitive and innovative environment online that allows for our best thinkers to step in and re-imagine content moderation and free speech online, ${ }^{190}$ while letting Section 230 do what it does best. The result of an online world dominated by protocols would be very similar to what the Stop the Censorship Act tries to accomplish but would keep Section 230 intact, decentralize the monopolistic power of Big Tech ICSs, and preserve the valuable network effects.

\section{CONCLUSION}

Section 230 provides that ICS providers will not be liable for "any action voluntarily taken in good faith to restrict access to or availability" to third-party content, "whether or not such material is constitutionally protected," 191 and it should stay that way. Courts have recently thrown out the notion that the Internet is a public square, ${ }^{192}$ and Section 230 does its part to regulate these private Internet spaces. ${ }^{193}$ So

187. MASNICK, supra note 14 (italics added).

188. Id.

189. Id.

190. Id.

191. 47 U.S.C. $\S 230(c)(2)($ A).

192. Prager Univ. v. Google LLC, 951 F.3d 991, 997 (9th Cir. 2020) ("YouTube may be a paradigmatic public square on the Internet, but it is 'not transformed' into a state actor solely by "provid[ing] a forum for speech." (quoting Manhattan Cmty. Access Corp. v. Halleck, 139 S. Ct. 1921, 1930, 1934 (2019)).

193. See generally Jess Miers, Section 230: What You Don't Know Might Destroy the Internet, YoUTUBE: TEDX TALKS (Apr. 11, 2019), https://www.youtube.com /watch?v=7EGRRM_kMac\&feature=youtu.be\&t=585 [https://perma.cc/QH7V$\mathrm{XNBJ}]$. 
[Vol. 8

what is broken about the Internet? It is not Section 230, and if it is not broken, do not fix it.

There is no simple solution to fix the challenges of over-moderation or under-moderation online that lead to content moderation and free speech issues. ${ }^{194}$ Repealing or weakening Section 230 will not fix over-moderation - or even under-moderation - online, however, allowing and fostering competition against Big Tech in the ICS sector in the right way and using the right tools can. Existing antitrust laws combined with a fundamental change to the digital infrastructure of the Internet by switching to a more protocol-oriented Internet are good places to start.

194. MASNICK, supra note 14. 